\title{
Improving the Performance of Human Body with Far Infra-Red Rays Reflecting Textiles
}

\author{
Mayur Basuk* \\ Wool Research Association - Center of Excellence for Sportech, India
}

Submission: September 07, 2018; Published: October 16, 2018

*Corresponding author: Mayur Basuk, Assistant Director, Wool Research Association - Center of Excellence for Sportech, Maharashtra, India, Thane- 400607, Tel: +91-9699821340/+91-22-2586-8109; Fax: +91-22-2531-8365; Email: mbasuk@wraindia.com/mayurtex.basuk@gmail.com

Abstract

All living organisms are subjected to the natural electromagnetic radiation reaching the earth from the sun. Living organisms experience the beneficial as well as adverse effects of it at all levels, starting from sub-cellular organelles and ending with the whole body. Nowadays, specialty FIR emitting heat lamps and garments made up of filaments (fibers) impregnated with FIR emitting nanoparticles are becoming used to deliver these thermal radiation effects. The Present paper explores the use of FIR in textiles, test method, Present status for far infrared reflecting textiles and global market along with future innovations in the field.

Keywords: Far infrared radiation; Blackbody radiation; FIR test methods; Global market; FIR Emitting ceramics; Fibers

\section{Introduction}

Protection against extreme weather, especially cold, has been primary purpose of clothing and heating/warming fabrics serve just the purpose. In spite of several challenges in smart fabrics and commercialization of new technologies, there is sense of optimism, thanks to the advent of technologies aiming to perfect the heating and /or heat retention technologies. Manufacturers and innovators have been tirelessly working on to improve the capacity of fabrics or garments to provide maximum comfort in winter. Evolution of various technologies and strategical combination of technologies has made it possible to have different solutions for different conditions.

Far infrared (FIR) radiation $(\lambda=3-100 \mu \mathrm{m})$ is a subdivision of the electromagnetic. Thermal radiation (or infrared) is a band of energy in the complete electromagnetic spectrum and it has been used effectively for millennia to treat/ease certain maladies and discomforts. With the development of better technology to deliver pure far infrared radiation (FIR), the benefits from its effects have widened. Technological advances have provided new techniques for delivering FIR radiation to the human body. Specialty lamps and saunas, delivering pure FIR radiation (eliminating completely the near and mid infrared bands), have become safe, effective, and widely used sources to generate therapeutic effects. Fibers impregnated with FIR emitting ceramic nanoparticles and woven into fabrics, are being used as garments and wraps to generate FIR radiation and attain health benefits from its effects [1].

\section{What is FIR Radiation?}

With respect to the complete electromagnetic radiation spectrum, the infrared radiation (IR) band covers the wavelength range of $750 \mathrm{~nm}-100 \mu \mathrm{m}$, frequency range of $400 \mathrm{THz}-3 \mathrm{THz}$, and photon energy range of $12.4 \mathrm{meV}-1.7 \mathrm{eV}$. It lies between the long wavelength red edge of the visible and the short edge of the terahertz (starting at $3 \mathrm{THz}$ ) spectral bands (Figure 1).

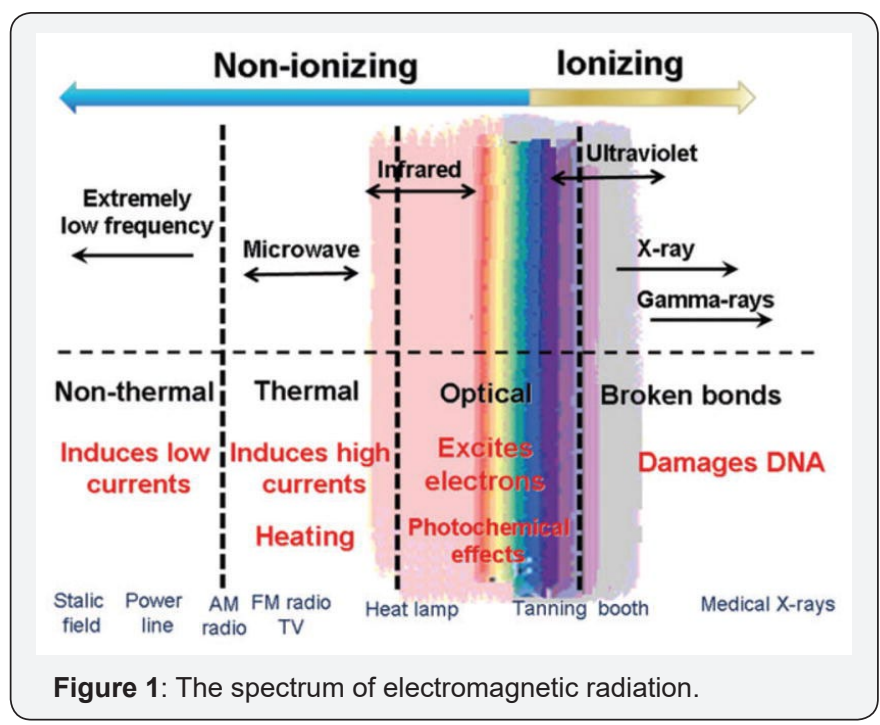

Table 1: CIE classification of IR radiation.

\begin{tabular}{|c|c|c|}
\hline $\begin{array}{c}\text { Name/Abbrevi- } \\
\text { ation }\end{array}$ & Wavelength & $\begin{array}{c}\text { Photon Energy } \\
\text { (THz) }\end{array}$ \\
\hline $\begin{array}{c}\text { Near infrared/ } \\
\text { IR-A }\end{array}$ & $0.7-1.4 \mu \mathrm{m}(700-1400 \mathrm{~nm})$ & $215-430$ \\
\hline Mid infrared/IR-B & $1.4-3.0 \mu \mathrm{m}(1400-3000 \mathrm{~nm})$ & $100-215$ \\
\hline Far infrared/IR-C & $\begin{array}{c}3.0-100 \mu \mathrm{m}(3000 \mathrm{~nm}- \\
0.1 \mathrm{~mm})\end{array}$ & $3-100$ \\
\hline
\end{tabular}

The classification of the International Commission on Illumination (CIE) has three sub-divisions for the IR radiation as 


\section{Current Trends in Fashion Technology \& Textile Engineering}

given in Table 1. An alternative classification provided in ISO 20473 standard for the sub-division of the IR ranges is given in Table 2. In the IR radiation bands, only FIR transfers energy purely in the form of heat which can be perceived by the thermoreceptors in human skin as radiant heat [1]. Not only is FIR absorbed by the human body, but it is also emitted by the body in the form of black body radiation $(3-50 \mu \mathrm{m}$ with an output peak at $9.4 \mu \mathrm{m})$.

Table 2: ISO 20473 standard for sub-division of the IR.

\begin{tabular}{|c|c|}
\hline Name/Abbreviation & Wavelength $(\mu \mathrm{m})$ \\
\hline Near IR, NIR & $0.78-3$ \\
\hline Mid IR, MIR & $3.0-50$ \\
\hline Far IR, FIR & $50-1000$ \\
\hline
\end{tabular}

It is difficult to perceive a world without innovation. The essential benefit of development is a better world and a safer life. There are instant solutions to all problems and the solutions are far simpler today. Industrial sector constantly develops ideas and products that serve the society at large. In the textile sector too, innovation has brought forward dramatic changes and this transformation is still running its course. With mercury steeply going down in the Northern hemisphere, the market for winter clothing is warming up. The advancement in textile has ensured that there are many high performances winter clothing to combat the dropping temperature. The Far Infrared (FIR) fibers in textile are among many innovations that use heating elements in cold weather clothing. FIR is also an integral part of therapeutic segment of clothing.

\section{Heat Generation}

\section{Infrared radiation}

These fabric technologies utilize IR rays (wavelengths ranging between $700 \mathrm{~nm}$ to $1 \mathrm{~mm}$ ) for Sunlight's electromagnetic radiation or body heat for thermoregulation when the temperature around body is low (Figure 2). IR has three broad categories, Near Infrared, Mid-Infrared and Far Infrared. While IR radiation is more often defined by the heating function, Far Infrared has specialized function (discussed in the next section). Many fabrics have been developed enable with IR radiation capabilities. The main additives imparting IR capability are ceramics, trace elements, metal oxides, etc. These materials have common characteristics of being able to absorb and store heat (i.e. high heat capacity) and release it when the surrounding temperature is low. Both yarn inherent and print versions are available in market for imparting IR emitting property to the fabrics. A different approach has also been taken to reflect IR radiation (generated by our body), thus preventing heat loss when in cold conditions.

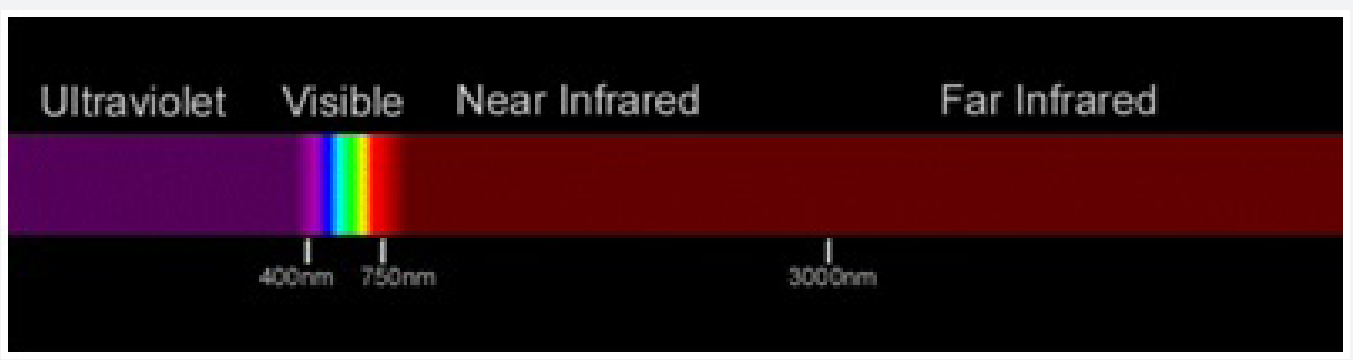

Figure 2

\section{Far infrared radiation}

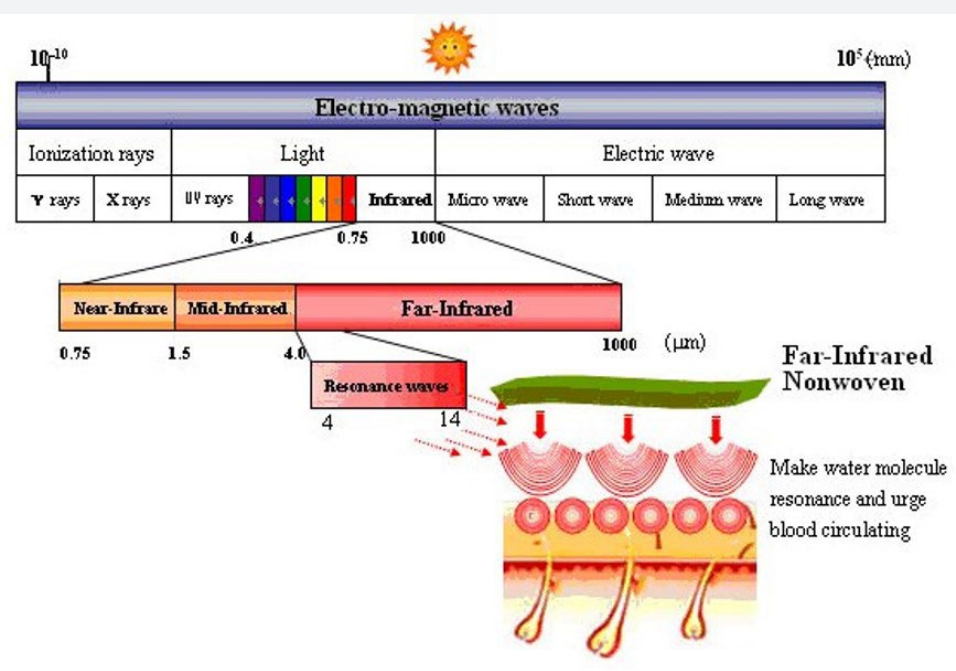

Source: http://www.quantumacceleration.net/BioMat.html

Figure 3 


\section{Current Trends in Fashion Technology \& Textile Engineering}

Although not typically heating technology, but FIR (higher wavelength section of IR spectrum) is often used in fitness and recovery applications owing to its 'internal heating' capability. The user does not necessarily experience heat by FIR radiation. Far infrared (FIR) radiation $(\lambda=3-100 \mu \mathrm{m})$ is a subdivision of the electromagnetic spectrum that has been widely studied for its biological effects (Figure 3). With the evolution of technologies to be able to filter specific wavelength range e.g. far infrared radiation (FIR), it has been made possible to achieve benefits of the radiations selectively. Nowadays, specialty FIR emitting heat lamps and garments made up of filaments (fibers) impregnated with FIR emitting nanoparticles are being used to deliver the thermal radiation effects. At the cellular level, the electromagnetic radiation interacts with living cells by altering cell membrane potentials and mitochondrial metabolism. FIR energy (photons with quantum energy levels of $12.4 \mathrm{meV}-1.7 \mathrm{eV}$ ) is absorbed by vibrational levels of bonds in molecules. The energy levels so reached lead to expansion of blood vessels, thinner body fluid and increased hydration capacity of water molecules.

Hygroscopic heating refers to generation of heat by absorbing moisture. Many polymers have the tendency to absorb moisture and the process of moisture absorption leads to heat generation (an exothermic process). The heat generated is termed 'heat of absorption' or 'absorption heat' and is an outcome of bond formation between water molecules and the yarns' polymer chain. Different yarns have different water absorption capabilities and the amount of heat generated can be different for different polymers owing to different chemistries. Some manufacturers have made efforts have to increase the absorption by chemically modifying the polymer and increasing the binding sites for water. In general, cotton, wool, rayon, etc. Fall in this category and have been used extensively for harnessing moisture to generate warmth to the wearer.

\section{Heat Retention}

While different methods have been discussed above to actively utilize different heat sources (e.g. body heat or external IR sources) as well as indirect heating (e.g. hygroscopic), the basic idea of conserving body heat by just creating a barrier for heat exchange with exterior still holds its value. Maintaining a still air microenvironment next to skin is one effective way to contain the warmth around body, as the air serves as an insulating layer. High gauge construction methods and hairy fibers (e.g. wool) serve the purpose in this aspect.

Some other strategic constructions have also been tried with varying success, as discussed further in the article.

\section{Understanding clothing insulation}

Clothing insulation is an important aspect of fabric performance as far as warm conditions are concerned. The capacity of the fabric to retain heat depends on several factors and its quantification has been a challenging exercise. CLO, or Clothing Insulation, is the measure of fabric's (or garment's) capacity to retain wearer's body heat and make her/him comfortable. While a CLO value of 0 represents naked person, CLO value of 1 is the amount of insulation that allows a person at rest to maintain thermal equilibrium in an environment at $21^{\circ} \mathrm{C}\left(\sim 70{ }^{\circ} \mathrm{F}\right)$ in a normally ventilated room $(0.1 \mathrm{~m} / \mathrm{s}$ air movement). Above this temperature the person so dressed will sweat, whereas below this temperature the person will feel cold. CLO values can be assigned to fabrics, garments as well as ensembles of garments. The below Table 3 is general (neither standard nor extensive) representation of different garments' CLO values.

Table 3:

\begin{tabular}{|c|c|}
\hline Ensemble Description & CLO \\
\hline Walking shorts, short-sleeved shirt & 0.36 \\
\hline Trousers, short-sleeved shirt & 0.57 \\
\hline Trousers, long-sleeved shirt & 0.61 \\
\hline Same as above, plus suit jacket & 0.96 \\
\hline Same as above, plus vest and T-shirt & 1.01 \\
\hline Trousers, long-sleeved shirt, long-sleeved sweater, T-shirt & 1.3 \\
\hline Same as above, plus suit jacket and long underwear bottoms & 0.74 \\
\hline Sweat pants, sweat shirt & 0.96 \\
\hline Knee-length skirt, short-sleeved shirt, panty hose, sandals & 0.54 \\
\hline Knee-length skirt, long-sleeved shirt, full slip, panty hose & 0.67 \\
\hline Long-sleeved pyjama top, long pyjama trousers, short 3/4 sleeved robe, slippers (no socks) & 1.1 \\
\hline Knee-length skirt, long-sleeved shirt, half-slip, panty hose, suit jacket & 1.04 \\
\hline Ankle-length skirt, long-sleeved shirt, suit jacket, panty hose & 1.1 \\
\hline Long-sleeved coveralls, T-shirt & 0.72 \\
\hline Overalls, long-sleeved shirt, T-shirt & 0.89 \\
\hline
\end{tabular}




\section{Current Trends in Fashion Technology \& Textile Engineering}

\begin{tabular}{|c|c|c|c|}
\hline Garment Description & CLO & Garment Description & CLO \\
\hline \multicolumn{2}{|l|}{ Underwear } & \multicolumn{2}{|l|}{ Sweaters } \\
\hline Bra & 0.01 & Sleeveless vest & $0.12-0.22$ \\
\hline Panties & 0.03 & Long-sleeve & $0.25-0.37$ \\
\hline Men's briefs & 0.04 & \multicolumn{2}{|l|}{ Trousers and Coveralls } \\
\hline T-shirt & $0.08-.0 .09$ & Short shorts & 0.06 \\
\hline Half-slip & 0.14 & Walking shorts & 0.08 \\
\hline Long underwear bottoms & 0.15 & Straight trousers & $0.15-0.25$ \\
\hline Full slip & 0.16 & Sweatpants & 0.28 \\
\hline Long underwear top & 0.2 & Overalls & 0.3 \\
\hline \multicolumn{2}{|c|}{ Shirts and Blouses } & Coveralls & 0.49 \\
\hline Tube Top & 0.06 & Multi-component with filling & 1.03 \\
\hline Sleeveless/scoop-neck blouse & 0.12 & Fiber-pelt & 1.13 \\
\hline Light blouse with long sleeves & 0.15 & \multicolumn{2}{|l|}{ Sleepwear and Robes } \\
\hline Short-sleeve knit sport shirt & 0.17 & Sleeveless short gown (thin) & 0.18 \\
\hline Short-sleeve dress shirt & 0.19 & Sleeveless long gown (thin) & 0.2 \\
\hline Long-sleeve dress shirt & 0.25 & Short-sleeve hospital gown & 0.31 \\
\hline Long-sleeve flannel shirt & 0.34 & Short-sleeve short robe (thin) & 0.34 \\
\hline Long-sleeve sweatshirt & 0.34 & Short-sleeve pyjamas (thin) & 0.42 \\
\hline Long sleeves with turtleneck blouse & 0.34 & Long-sleeve long gown (thick) & 0.46 \\
\hline \multicolumn{2}{|c|}{ Dress and Skirts } & Long-sleeve short wrap robe (thick) & 0.48 \\
\hline Skirt & $0.14-0.23$ & Long-sleeve pyjamas (thick) & 0.57 \\
\hline Sleeveless, scoop neck & $0.23-0.27$ & Long-sleeve long wrap robe (thick) & 0.69 \\
\hline Short-sleeve shirtdress (thin) & 0.29 & Body sleep with feet & 0.72 \\
\hline Long-sleeve shirtdress & $0.33-0.47$ & \multicolumn{2}{|l|}{ Footwear } \\
\hline \multicolumn{2}{|c|}{ Jackets and Vests } & Ankle-length athletic socks & 0.02 \\
\hline Sleeveless vest & $0.1-0.17$ & Pantyhose/stockings & 0.02 \\
\hline Single-breasted & $0.36-0.44$ & Shoes/Sandals/thongs & 0.02 \\
\hline Double-breasted & $0.42-0.48$ & Slippers (quilted, pile lined) & 0.03 \\
\hline Down Jacket & 0.55 & Calf-length socks & 0.03 \\
\hline Coat & 0.6 & Knee socks (thick) & 0.06 \\
\hline Parka & 0.7 & Boots & 0.1 \\
\hline
\end{tabular}

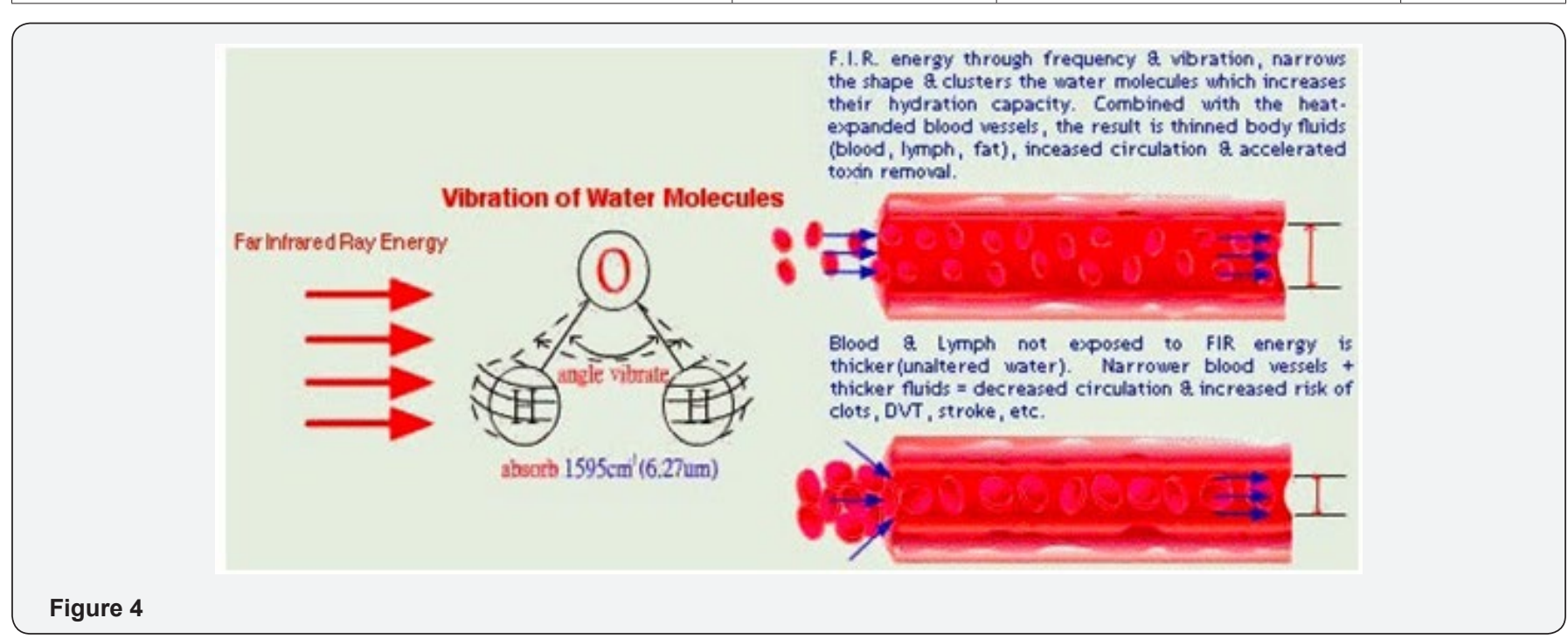




\section{Current Trends in Fashion Technology \& Textile Engineering}

Apart from the material and fabric construction, important factors determining insulation include posture and activity of the wearer. As mentioned earlier, CLO is represented as with respect to a person at rest in a controlled environment, so a walking or running person will experience different insulation by the same fabric/garment than being immobile. In general, body motion decreases the insulation of a clothing ensemble by increasing air movement through spaces between yarns in the fabric and/ or causing air motion within the garment. This effect varies considerably depending on the nature of the motion and of the fabric. This is why, an accurate estimates of clothing insulation for an active person is very challenging. In a nutshell, the specifications and requirements for each garment will depend on the season as well as end use of the garment (Figure 4).

\section{Heat retention strategies}

There are different ways to retain body heat next to the skin, by creating a micro-environment. Most of the strategies are focused around interfering in the exchange of heat or air (which is supposed to transfer heat by convection) between the two sides of the garment. Some of the methods have been listed below.

\section{Hollow yarns}

Retained air inside the hollow yarn as "temperature cushion" Going down to the yarn/fiber level, the trapped air helps in maintaining a microenvironment with still air that serves as an insulating barrier for heat exchange between its two sides. Apart from assisting in heat retention, hollow yarns also help in maintaining the lofty and heavy look without contributing a lot to the fabric weight (Figure 5).

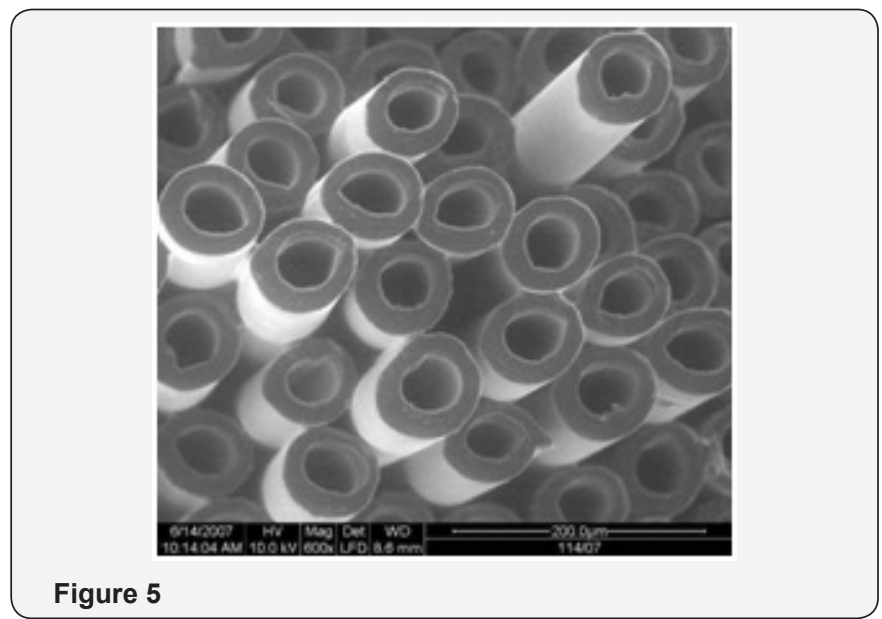

\section{Spacers}

Spacers are two or more layers of fabrics connected by filament yarns traversing between the layers as bridges.

Spacers have been tried out for various applications, mostly to replace foam and heavy fabrics for insulation. The capability to hold air in space between its two (or more) layers imparts spacers the ability to insulate heat across its thickness. The disadvantages of using spacers have been the drape and thickness of the fabric. Most of the times, the garment ends up with space suit like appearance, due to the stiff nature of connecting filaments, a prerequisite in maintaining the spacer structure. Softer connecting filaments have been tried but that compromises the spacer structure, leading to instability of the air-pockets and so reduction in heat retention (Figure 6).

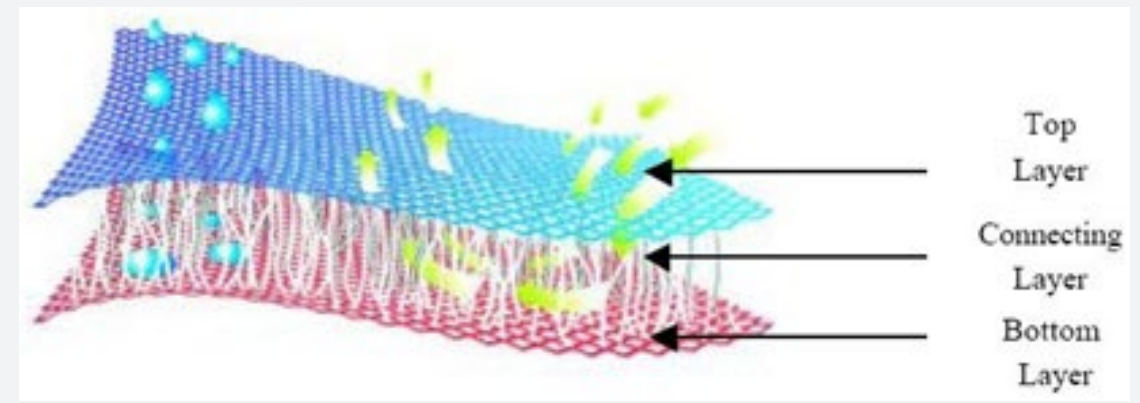

Figure 6

\section{Tortured air passage}

As mentioned earlier in this article, yarns with hairy surface contribute to heat retention by disturbing the passage air flow. This property, along with hygroscopic heat generation, has made wool the material of choice for winter wear. Other yarns, including polyester, have also been modified to achieve some level of heat retention by hindering the air passage, e.g. spun yarns, ATY, yarns with varied shrinkage, etc.

\section{Quilted fabrics}

In line with blocking or disturbing the air passage, various attempts have been made to develop warming fabrics structures by quilting. Garments with down and other fills have been very successful as they are able to not only block the cold waves from outside but also aid in heat retention by keeping the warmth inside the garment, again by creating the still air micro-environment.

\section{Layered clothing}

It has been widely understood that layered fabrics are able to retain more heat than single layer of thickness equal to all the layer, added together. This advantage is achieved by the still air retained between the layers in the arrangement. Additionally, different layers perform different functions based on their position. Usually at least three layers are identified as follows:

1) Inner Layer (also called base layer or first layer): Usually with the soft hand feel, this layer is designed to provide comfort by keeping the skin dry. 


\section{Current Trends in Fashion Technology \& Textile Engineering}

2) Mid Layer (or insulating layer): this is where warming/ heating function is imparted. The fabrics with inherent heating properties (dry heat or hygroscopic heat generation) are usually slotted in the mid layer. A heated layer not only helps to create a warm microenvironment but also helps in insulation by disturbing the energy (heat) gradient across its two sides.

3) Outer Layer: Also called Shell layer, it works as protection over the other two layers. For heavy winter applications, waterproofing/repellency has been recommended to ward off snow or water coming in contact with the garments' outer surface. Another layer of insulation is provided by this layer as air is held between mid- and outer layer.

\section{Active heating}

In recent past, interdisciplinary research has made it possible to generate heat by external sources, e.g. powered systems, to heat up the garments or parts of a garment (Figure 7). Different components have been made to heat up and make the wearer feel comfortably warmed up in extreme cold conditions. Jackets, gloves, balaclavas, and various other products are available in the market which can heat up, using a power source, to a desired level to provide comfort from cold exterior conditions. The heating is achieved by many methods, dominated by use of conductive yarns. Conductive yarns are many based on core-shell structure with polyester (and other polymers) core providing the mechanical properties while the metal shell (usually copper) is meant to conduct heat across its length. The yarns are integrated into the fabric either by weaving or by embroidery, special arrangements need to be made to knit the yarns into the fabrics. The challenges include yarn breakage, bending limitations for metal yarns, need of insulation, etc. Insulation is often addressed by adding another membrane of coating on the conductive parts of the fabric. Some new advancements have been to reverse the core-shell arrangement, having metal in the core and polymer in the shell (something like regular wires, but at a small scale of yarn thickness). Other methods include use of carbon fibers, conductive prints and membranes, using graphene, although they are in early stages of their application.

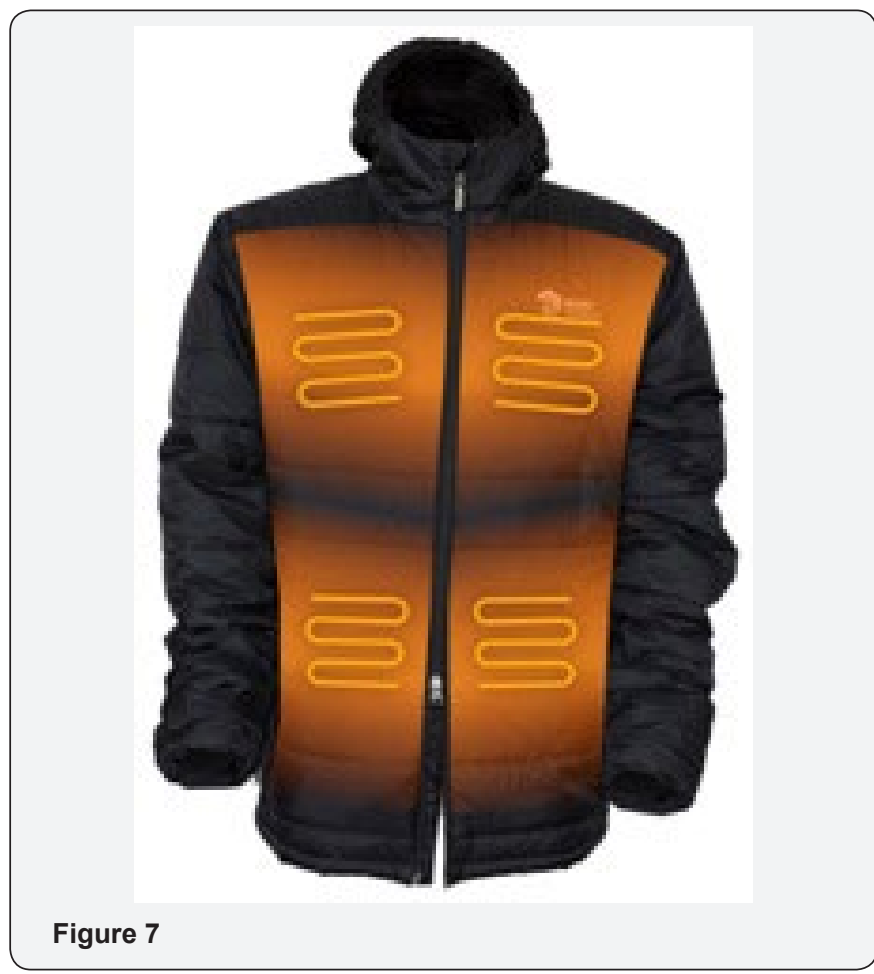

\section{Phase change materials}

PCMs, or phase change materials, draw special attention when it comes to thermo regulation. Phase change materials are able to regulate their surrounding temperature by changing their phase at specific temperature. The most common example is 'water'. At its freezing point, i.e. $0^{\circ} \mathrm{C}$ (or $32^{\circ} \mathrm{F}$ ) water transitions between liquid and solid phases, converting to liquid (water) above and to solid (ice) below this temperature. For practical applications in textiles, the temperature needs to be around body temperature. The phase change that is suitable for textile application is 'solidliquid' phase change which takes place at its melting point. The energy exchanged in this process is called 'heat of fusion' Commercially, most common materials used are paraffin or short chain lipids, which have wide range of melting points depending on chain length. Manufacturers are able to tailor the melting points by controlling the chain lengths (Figure 8).

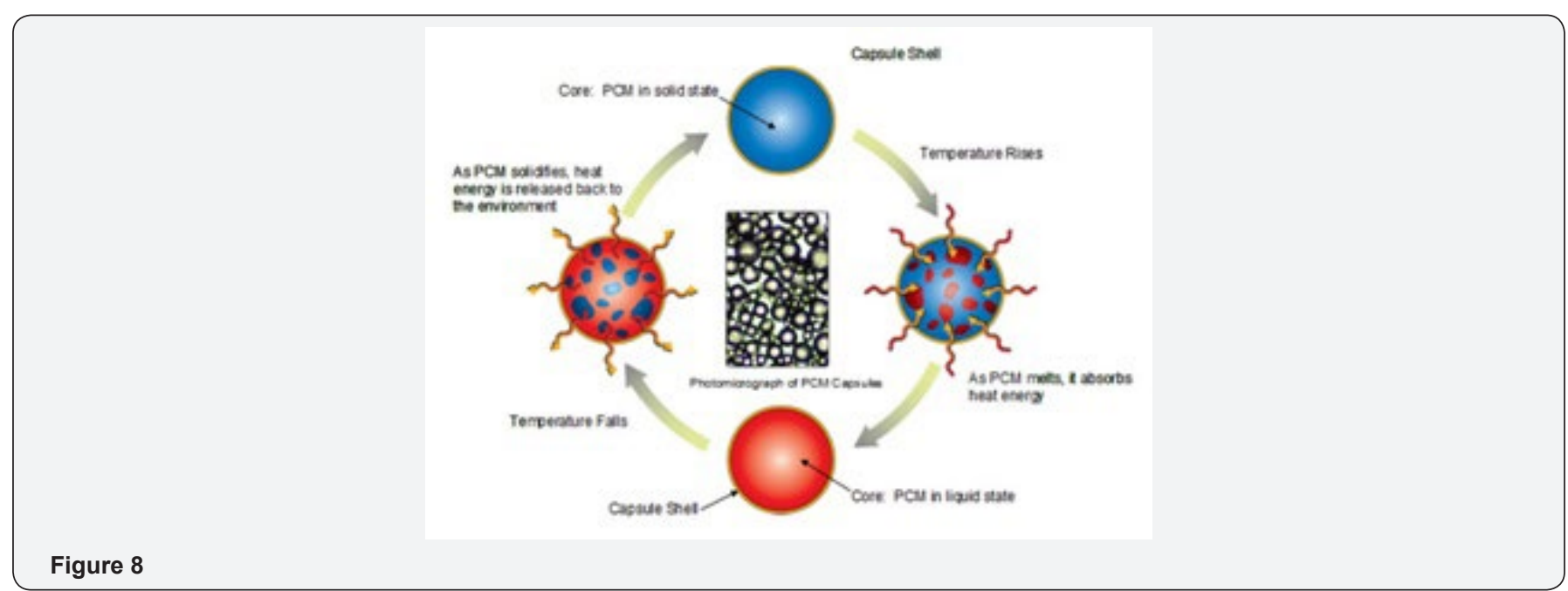


Other materials used as PCMs are some carbohydrates, salt hydrates, etc. There are also solid-solid phase transitions (between crystal lattice structures) found in some materials, leading to significant amount of heat. Textile industry however has been limited to using liquid-solid transition of materials for practical reasons. PCMs are loaded into fabrics in three different ways: at yarn level (for synthetic yarns), as fabric coating, and as fabric treatment (usually involving PCM loaded nanoparticles) wherein the material reaches and binds to individual fibers/ filaments in the yarn. PCM usage has met with many challenges, specially related to loading efficiency and saturation (once the phase transition has taken place and no heat exchange can take place). Saturation can be delayed by increasing the loading which is limited by loading capacity of the micro/nanoparticles or mechanical strength of the yarn (in case of yarn loading). Attempts have been made to increase PCM loading in particles by reducing the wall thickness, thus increasing the core volume. This requires shell to have additional strength which was achieved by crosslinking, mostly by formaldehyde. Concerned by health concerns, many manufacturers have successfully attempted to increase the particle stability by alternative cross-lining agents.

\section{Present Status for Far Infrared Reflecting Textiles}

A combination of polypropylene and special lead-free bioceramics is used to create these fibres. The ceramic is responsible for emitting the far infrared rays. The basic structure of this fibre is based on the fact that energy emission is part of human body. The bio-ceramic converts thermo energy of human body into far infrared rays that generate deep but gentle heating. The health benefits of FIR textile range from keeping wearer's body warm, restoring physical function by getting rid of fatigue, relieving muscle pain, using to ease pain of arthritis and bronchitis. Such type of textile fabric also boasts of anti-bacterial and deodorantlike properties. All these features make far infrared fabrics suitable for health care products. The markets are already selling FIR trousers, undergarments, knee pads, nursing neck and stomach, socks, cushion, bedspread, bedding and shoulder pad. FIR clothing also proves to be a boon to regular joggers, athletes and defense personnel during cold weather [2].

\section{Asian roots}

The infrared concept has long been rooted in the cultures related to the Asian domains. Asian therapies often emphasise importance of blood circulation for well-being. Chinese Qi Gong is known to advocate this theory. Though, other products like infrared heat lamps etc. were easily available in market, FIR clothing is a comparatively new development. FIR fibre was developed by a Californian company in 2003. Since then, many brands have been launched in the global market. The fabric has already proved its mettle in field of extreme sports. International sports brands are also taking keen interest in developing special range of sports gear that can give promising performance during colder temperatures. Medical fraternity too has shown support to this fabric for use in diabetic foot care, bedding and mattresses. Brands are also promoting shapewear and sliming lingerie designed on far infrared mechanisms. The first company to launch FIR textile Hologenix has recently announced its collaboration with Puma on a line of men's athletic apparel inspired by Olympian Usain Bolt. Hologenix's FIR fabrics have found a place in markets of United States, Taiwan, South Korea, etc. One of the commercial versions of FIR-emitting textiles for apparel was marketed by the French company HT Concepts. The move has expanded the reach of infrared technology into several sectors, such as fashion apparel, bedding, and technical accessories that include helmets and automotive seating. Among the latest innovation in FIR, Swiss company Schoeller's version of FIR reflecting technology has been applauded worldwide. The company's fabric uses titaniummineral matrix that can be integrated into membranes and coatings [3].

The energear textile technology was developed in 2010 for Schoeller textiles and is now available for diverse markets. energear can be integrated into textiles in different ways such as through membranes and coatings. According to Schoeller, to harness the benefits of this technology for a textile print, a minimum of $30 \%$ of a shirt or other garment can be finished with the laundry-permanent energear print. Schoeller Technologies has also developed some design suggestions for the purpose and depending on the blend, the printing paste with energear results in a grey to silver-metallic look. Schoeller says the process is generating enormous interest in various areas and is officially launching at Outdoor. First consumer products in Schoeller fabrics will be available beginning this summer from, among other brands, Alberto (golf pants) and Bugatti (lifestyle jacket). Schoellers FIR expertise was applauded by Lee Davis, race car driver and founder of Luna C Clothing for auto racing. In one of his interviews, Davis vouched for FIR fabric's high-performance stating that the technology captures the far infrared rays and puts them back into the body, which results in higher concentration and focus, a lower pulse rate and lowers the time body takes to recover. Schoeller has launched a variety of technical fabrics based on FIR technology. The outerwear range includes denim, water-repellent viscose or polyester blends for outerwear and wool blends [4].

\section{Testing of Far Infrared Reflecting Textiles}

The far infrared textile processing includes mixing of raw materials, coating, lamination and submerging. As products made of mixing of raw materials deliver the same durability of the fiber, the wash-resistance test would not necessary. For products come of coating, lamination and submerging processes will have to have the 10 times wash-resistance test based on AATCC 135 (1) (III) (A) iii prior to conducting the performance test. The performance test is conducted in ambient temperature and the criteria are given as below:

\section{Test method}

Performance of a textile material or a garment is tested by several methods. Listed below are some test standards suitable for respective applications [5]. 


\section{Current Trends in Fashion Technology \& Textile Engineering}

Thermal Insulation (Heat retention capability): This property of a fabric or garment is tested by the following standards:

1. Thermal Transmittance of Textile Materials (ASTM D 1518)

2. Measuring Thermal Insulation of Clothing using a heated manikin (ASTM F 1291)

3. Thermal and Evaporative Resistance of Clothing Materials using a sweating hot plate (ASTM F 1868-02)

\section{Hygroscopic heat generation}

This test determines the fabrics capability to generate heat merely by absorbing moisture (heat of absorption). The test involves measurement of fabric temperature, kept on the plate, while relative humidity is increased from $10 \%$ to $90 \%$ in a chamber with controlled temperature of $20^{\circ} \mathrm{C}$. The test has been developed by GAP and for a fabric to be categorized as hygroscopic heat generating fabric, the rise in temperature must be $2{ }^{\circ} \mathrm{C}$ more than the control (similar regular fabric or blank).

\section{Dry heat generation}

While there is no standard test for measuring dry heat (not hygroscopic) generation, most innovator study the performance by using a heat source (e.g. $500 \mathrm{~W}$ halogen bulb) set at a fixed distance (equidistant) from the control as well as experimental fabric and measuring the temperature of the fabrics at set time points, using temperature sensors. For consistency of the study, the experiment must be performed in the controlled environment (temperature, relative humidity, etc.). The test is often extended to cooling phase as well, i.e. measuring the temperature when the heat source is turned off. This gives an idea of fabrics property to retain heat [6]. Test methods used for the evaluation of the performance of Far Infrared textile are illustrated as Table 4.

Table 4: Test methods

\begin{tabular}{|c|c|c|}
\hline \multicolumn{2}{|c|}{ Test Item } & Equipment \\
\hline \multirow{2}{*}{ Far Infra-red Characteristics } & $\begin{array}{c}\text { Far Infrared } \\
\text { Spectral Emis- } \\
\text { sivity }\end{array}$ & $\begin{array}{c}\text { Infrared spectro- } \\
\text { photometer \& Black } \\
\text { Body }\end{array}$ \\
\cline { 2 - 3 } & $\begin{array}{c}\text { Re- radiated } \\
\text { Characteristics }\end{array}$ & $\begin{array}{c}\text { 45-degree parallel } \\
\text { radiation }\end{array}$ \\
\hline Temperature Characteristics & Skin temperature & $\begin{array}{c}\text { Thermo Graph, } \\
\text { Thermal Imager }\end{array}$ \\
\hline
\end{tabular}

\section{Global Market}

Aging population, record breaking temperature in winter and increase in purchase by urban population, are some of the reasons that back FIR fabric. The growing need of this fabric has led to market expansion of functional fabrics in China and Taiwan. In recently concluded Autumn-2014 edition of Intertextile Shanghai Apparel Fabrics held in China, FIR was among the most soughtafter functional fabrics. China has entered third grade research on high stimulation differentiated fibres including far infrared. The United States, Europe, Australia, etc. import far infrared textile from Taiwan, China and other countries to meet the rising demand of the fabric Table 5 .

Table 5

\begin{tabular}{|c|c|}
\hline Test Item & Sample for Testing \\
\hline $\begin{array}{c}\text { Far Infra-red Character- } \\
\text { istics }\end{array}$ & $\begin{array}{c}\text { Sample cut from Finished or half-finished } \\
\text { products (fabric) At least } 5 \mathrm{~cm} \times 5 \mathrm{~cm} \text { for } \\
\text { opaque sample Triple of the above size for } \\
\text { transparent sample }\end{array}$ \\
\hline $\begin{array}{c}\text { Temperature Character- } \\
\text { istics }\end{array}$ & $\begin{array}{c}\text { Finished product the difference of fabric } \\
\text { weight between testing sample and com- } \\
\text { parative sample should within } 5 \% .\end{array}$ \\
\hline
\end{tabular}

\section{Further innovations}

The emphasis of textile companies is now on increasing performance and enhancing function of far infrared textile. Technical textile manufacturers are generally in good shape, the fact which indicates easy flow of funds into further research and development of far infrared products. The fabric has already entered the world of fashion and the acceptance is humbling so far. Continuous innovation has made this textile a rage across the world and leading companies along with international brands are diversifying FIR textile further, which is expected to lead to growing awareness and acceptance among prospective consumer [7].

\section{Conclusion}

Far-infrared is one band of the solar electromagnetic lightwave ranging in wavelength from $3 \mu \mathrm{m}$ to $1000 \mu \mathrm{m}$. Far-infrared textiles are made with blends of polymer and Nano- or microceramic powder spun together with synthetic cotton, natural cotton and other fibers to make yarns and fabrics. Far-infrared materials can also be added during after treatment of an ordinary fabric. Far-infrared textiles absorb sunlight, or heat from human body, and pass the far-infrared - wavelength 4 to $14 \mu \mathrm{m}$ - back to the human body. This specific range of far-infrared is reputed to be most useful to the human body and is called "the rays of life" or "biogenetic rays." When far-infrared rays strike the human body, their frequency is consistent with that of the body's cellular movement. Far-infrared materials are particularly effective during activities in High Mountain and snowy areas. If it can be proved that non-heating FIR has real and significant biological effects, then the possible future applications are wide ranging. Not only could bandages and dressings made out of NIR emitting fabrics be applied for many medical conditions and injuries that require healing, but there is a large potential market in lifestyle enhancing applications. Garments may be manufactured for performance enhancing apparel in both leisure activities and competitive sports areas. Cold weather apparel would perform better by incorporating FIR emitting capability and sleeping environments could be improved by mattresses and bedding emitting FIR.

\section{Acknowledgement}

The review study is the part of the R \& D project sponsored by Ministry of textiles, Govt. of India. The author of this paper is thankful to the Director and Management of Wool Research 


\section{Current Trends in Fashion Technology \& Textile Engineering}

Association, Thane for giving their unremitting support and guidance.

\section{References}

1. Fatma Vatansever, Hamblin MR (2012) Far infrared radiation (FIR): its biological effects and medical applications. Photonics Lasers Med 4 255-266.

2. www.fiber2fashion.com
3. https://www.innovationintextiles.com/far-infra-red-technology-canbe-printed-onto-fabrics/

4. https://www.schoeller-textiles.com/en/technologies/energear

5. Test Method of Specified Requirements of Far Infrared Textiles. FTTSFA- 010

6. http://alpinecreations.com/thermal-management-technologiestextiles

7. Miao, Dagang (2015) Fabrication of high infrared reflective textiles by magnetron sputtering technology.

\section{Your next submission with Juniper Publishers will reach you the below assets}

- Quality Editorial service

- Swift Peer Review

- Reprints availability

- E-prints Service

- Manuscript Podcast for convenient understanding

- Global attainment for your research

- Manuscript accessibility in different formats

( Pdf, E-pub, Full Text, Audio)

- Unceasing customer service

Track the below URL for one-step submission https://juniperpublishers.com/online-submission.php 